\title{
Incomplete Response/Stable Disease
}

National Cancer Institute

\section{Source}

National Cancer Institute. Incomplete Response/Stable Disease. NCI Thesaurus. Code C150562.

Persistence of one or more non-target lesions. 